\title{
New procedure to synthesize silver nanoparticles and their interaction with local anesthetics
}

This article was published in the following Dove Press journal:

International Journal of Nanomedicine

9 October 2013

Number of times this article has been viewed

\author{
Aurora Mocanu' \\ Roxana Diana Pasca' \\ Gheorghe Tomoaia ${ }^{2}$ \\ Corina Garbo' \\ Petre T Frangopol' \\ Ossi Horovitz' \\ Maria Tomoaia-Cotisel' \\ 'Chemical Engineering Department, \\ Babes-Bolyai University, ${ }^{2}$ Orthopedic \\ Department, luliu Hatieganu \\ University of Medicine and \\ Pharmacy, Cluj-Napoca, Romania
}

\begin{abstract}
Silver nanoparticles (AgNPs) were prepared in aqueous colloid dispersions by the reduction of $\mathrm{Ag}^{+}$with glucose in alkaline medium. Tetraethyl orthosilicate and L-asparagine were added as stabilizers of NPs. The AgNPs were characterized, and their interaction with three local anesthetics (procaine, dibucaine, or tetracaine) was investigated. Optical spectra show the characteristic absorption band of AgNPs, due to surface plasmon resonance. Modifications in the position and shape of this band reflect the self-assembly of metal NPs mediated by anesthetic molecules and the progress in time of the aggregation process. Zeta-potential measuring was applied in order to characterize the electrostatic stability of the NPs. The size and shape of the AgNPs, as well as the features of the assemblies formed by their association in the presence of anesthetics, were evidenced by transmission electron microscopy images. Atomic force microscopy images showed the characteristics of the films of AgNPs deposited on glass support. The effect of the anesthetics could be described in terms of electrostatic forces between the negatively charged AgNPs and the anesthetic molecules, existing also in their cationic form at the working $\mathrm{pH}$. But also hydrophobic and hydrogen bonding interactions between the coated nanoparticles and anesthetics molecular species should be considered.
\end{abstract}

Keywords: self-assembled nanostructures, UV-vis spectra, TEM, AFM, zeta potential

\section{Introduction}

Present research in the area of nanomaterials is highly focused on metal (mainly noble metal) nanoparticles (NPs), such as gold, silver, platinum, palladium, or hybrid NPs, in view of their unique characteristics that enable their application in biology and nanomedicine for diagnostics and therapeutics, medical imaging, biosensors, and drug carriers, as well as in molecular electronics, catalysis, and nanotechnologies. ${ }^{1-5}$ For various applications, particularly for biological and biomedical purposes, such NPs are mostly functionalized with biomolecules (drugs, amino acids, proteins), ${ }^{6,7}$ which confer them special biological features, biocompatibility, and colloidal stability. The performance of these NPs is also determined in large measure by their self-aggregation in solution or on different substrates when more or less ordered self-assemblies are built, presenting various sizes and arrangement of particles. ${ }^{8}$

Silver NPs (AgNPs) are of great interest for their various applications in microelectronics, photonics and photocatalysis, surface-enhanced Raman scattering, ${ }^{9-11}$ and as antibacterial and antimicrobial agents. ${ }^{12-16}$ Bioconjugates of AgNPs have also been prepared and their self-assembly investigated. ${ }^{17-20}$ Various methods, among them biogenic methods, ${ }^{12,14-16,20-27}$ have been used for the synthesis of AgNPs. Glucose is well known for reducing $\mathrm{Ag}^{+}$to $\mathrm{Ag}$ in alkaline solutions, and this method was also used
Chemical Engineering Department,

Faculty of Chemistry and Chemical Engineering, Babes-Bolyai University,

I I Arany János Street, Cluj-Napoca 400028, Romania

$\mathrm{Tel}+40264593833$

Fax +40 264590818

Email mcotisel@chem.ubbcluj.ro 
to obtain AgNPs, glucose being a "green" reagent. 12,22,25-27 In order to protect the obtained AgNPs, besides existing oxidation products of glucose in the reaction system, different stabilizing agents were added, such as gelatin, ${ }^{22,25}$ hemicelluloses, ${ }^{26}$ or starch. ${ }^{27}$

This work reports a new procedure to synthesize AgNPs, using glucose as reducing agent but with an original stabilizing system consisting of tetraethyl orthosilicate (TEOS) and L-asparagine. The obtained AgNPs are further used in interactions with three local anesthetics: procaine (2-[diethylamino] ethyl 4-aminobenzoate), tetracaine (2-[dimethylamino] ethyl 4-[butylamino]benzoate) - both amino esters - and dibucaine (2-butoxy- $N$-[2-\{diethylamino $\}$ ethyl]quinoline4-carboxamide), an amino amide (Figure 1).

We are interested in understanding the molecular mechanism of local anesthetics, particularly in interfacial phenomena, that occur at the biological membrane level. ${ }^{28-32}$ The acid-base properties and the protolytic equilibria of these anesthetics ${ }^{33,34}$ should play an important role in their interaction with the charged metal NPs, since they determine which molecular species are present in solution at a given $\mathrm{pH}$ value. Recently, we have investigated their interactions with gold NPs. ${ }^{35}$

\section{Materials and methods}

\section{Materials}

All chemicals used were of analytical grade or of the highest purity available. Silver nitrate $\left(\mathrm{AgNO}_{3}\right)$, TEOS $\left(\mathrm{Si}\left[\mathrm{OC}_{2} \mathrm{H}_{5}\right]_{4}\right)$, sodium hydroxide $(\mathrm{NaOH})$, procaine hydrochloride, and L-asparagine (2-amino-3-carbamoylpropanoic acid) monohydrate were purchased from Merck (Darmstadt, Germany). The D-(+)-glucose, tetracaine hydrochloride, and dibucaine hydrochloride were purchased from Sigma-Aldrich, St Louis, MO, USA. Absolute ethanol (from Merck) was used as a cosolvent for TEOS. All chemicals were used as received without further purification. Aqueous solutions were prepared with double-distilled water, which was further deionized (ie, the resistivity of $18 \mathrm{M} \Omega \cdot \mathrm{cm}$ ) in an Elgastat (Vivendi Water Systems Ltd, France) water-purification system.

Aqueous solutions of the anesthetics were prepared in the range of $0.001-0.1 \mathrm{M}$. All glassware was cleaned with a fresh solution of $\mathrm{HNO}_{3} / \mathrm{HCl}(3: 1, \mathrm{v} / \mathrm{v})$ or with sulfochromic solution, rinsed thoroughly with pure water, and dried before use.

\section{Preparation of silver nanoparticles}

For the reduction of silver nitrate in a diluted aqueous solution, glucose was used in the presence of TEOS and asparagine as a new system of stabilizing agents for AgNPs. An aqueous solution of $\mathrm{AgNO}_{3}(500 \mathrm{~mL}, 0.001 \mathrm{M})$ and an aqueous solution $(500 \mathrm{~mL})$ containing glucose $(0.5 \%)$, TEOS $(0.01 \%)$, and asparagine $(0.05 \%)$ were separately heated up to $50^{\circ} \mathrm{C}$, and then they were mixed. The $\mathrm{pH}$ was adjusted to 11 using sodium hydroxide. Then, the solution was heated under continuous stirring to $60^{\circ} \mathrm{C}$ until the color was pale yellow. The temperature was precisely maintained by circulating thermostated water at $60^{\circ} \mathrm{C}$ within an uncertainty of $0.1^{\circ} \mathrm{C}$.

\section{Methods of measurement}

Optical absorption spectra were obtained using a Jasco (Easton, MD, USA) ultraviolet-visible V-650 spectrophotometer with $10 \mathrm{~mm}$ path-length quartz cuvettes in the 190-900 $\mathrm{nm}$ wavelength range. The investigated samples were the silver colloidal solution and
A

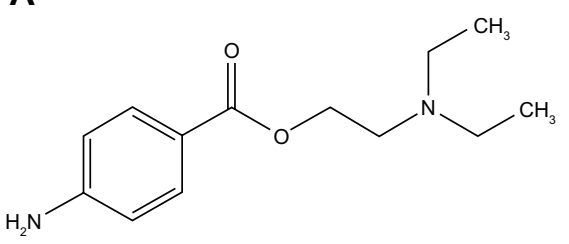

B<smiles>CCCCOc1cc(C(=O)NCCN(CC)CC)c2ccccc2n1</smiles>

C

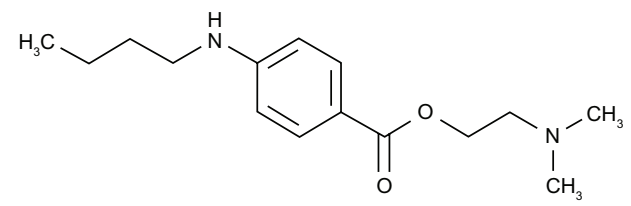

Figure I Molecular structure of procaine (A), dibucaine (B), and tetracaine (C). 
mixtures obtained by adding to $2 \mathrm{~mL}$ colloidal AgNP solution different amounts $(0.1,0.2,0.3,0.5$, and $1 \mathrm{~mL}$ ) of procaine, dibucaine, and tetracaine solutions (concentrations between $10^{-3}$ and $10^{-1} \mathrm{M}$ ). Measurements were made immediately after adding the anesthetic solution, and over time (from some minutes to several days). After the solutions were mixed with the anesthetics, the $\mathrm{pH}$ of all solutions remained about 5.5.

Zeta-potential measurements were performed using the Zetasizer Nano ZS (Malvern Instruments, Malvern, UK) on the colloidal silver solution and on its mixture in a $1: 1$ volume ratio with $10^{-2} \mathrm{M}$ procaine solution ( 2 minutes after mixing, at room temperature).

For transmission electron microscopy (TEM) imaging, the AgNP suspensions (approximately $7 \mu \mathrm{L}$ for each sample) in the absence or in the presence of anesthetics were deposited on the specimen grids and adsorbed for 1 minute. The excess solution was removed with filter paper, and the samples were air-dried. The AgNPs solution was mixed with the $10^{-2} \mathrm{M}$ procaine, the $10^{-2} \mathrm{M}$ tetracaine, and the $10^{-3} \mathrm{M}$ dibucaine solution respectively, in the $1: 1$ volume ratio for 30 seconds, before their deposition on the 300-mesh electrolytic copper grids, coated with a carbon layer. The samples were observed with TEM (JEM 1010; JEOL, Tokyo, Japan). TEM images were recorded with JEOL standard software.

Atomic force microscopy (AFM) images were taken on the nanostructured film of AgNPs obtained by vertical adsorption from the colloid solution on glass plates for 5 minutes and dried out in air. The same procedure was used for the mixtures of silver colloid solution and $0.01 \mathrm{M}$ anesthetic solutions in equal volumes. JEOL 4210 AFM equipment was operated in tapping mode, ${ }^{36}$ using standard cantilevers with silicon nitride tips (resonant frequency in the range of $200-300 \mathrm{kHz}$, spring constant $17.5 \mathrm{~N} / \mathrm{m}$ ). Different areas from $10 \times 10 \mu \mathrm{m}$ to $0.5 \times 0.5 \mu \mathrm{m}$ were scanned on the same film. The images (2-D and 3-D topographies, and cross-section profiles in the film along a selected direction) were processed by the standard procedures.

\section{Results and discussion Characterization of AgNPs}

The colloidal silver AgNP solution presented a yellow color. The visible absorption spectra of our AgNP dispersions showed a well-defined absorption band. The maximum of this absorption band due to surface plasmon resonance is at $406 \mathrm{~nm}$, near the values found for AgNPs

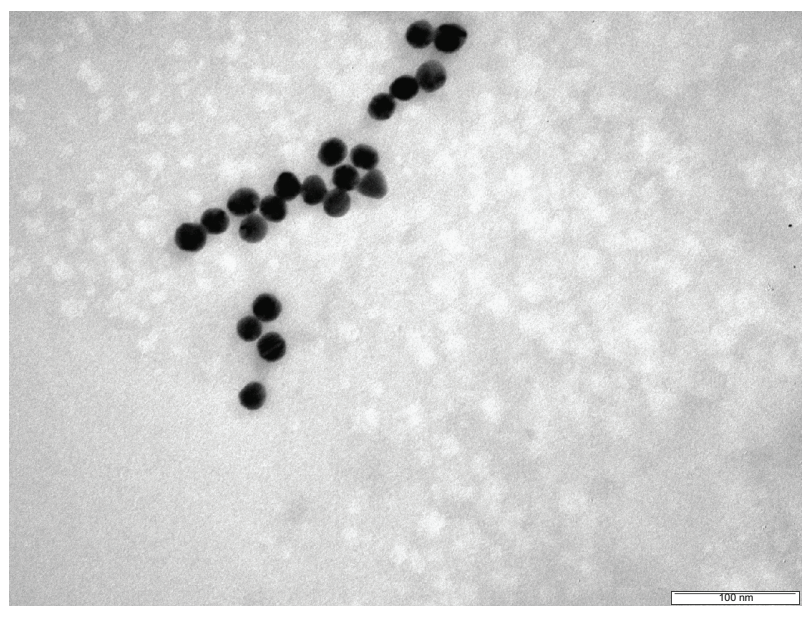

Figure 2 Transmission electron microscopy images for silver nanoparticles. The bar in the image corresponds to $100 \mathrm{~nm}$.

obtained by other synthetic methods. ${ }^{20}$ TEOS was introduced in this synthesis in order to stabilize and limit the growth of AgNPs by their coating with hydrated silica, as a result of its hydrolysis. Asparagine was used as a further stabilizing agent, its zwitterions probably being embedded in the silica coating of the AgNPs. This combination of stabilizing agents was used for the first time in the present work.

The charge of these AgNPs is negative. Zeta-potential measurements on the colloid solution gave an average value of $\zeta=-44.2 \mathrm{mV}$, showing rather high electrostatic stability of the NPs in an aqueous system (since $\pm 30 \mathrm{mV}$ is considered as the limiting value that assures stability). ${ }^{37}$

One of the TEM images for the AgNPs is given in Figure 2. Most of the particles present a spherical shape, but some polyhedral forms could also be observed. A slight

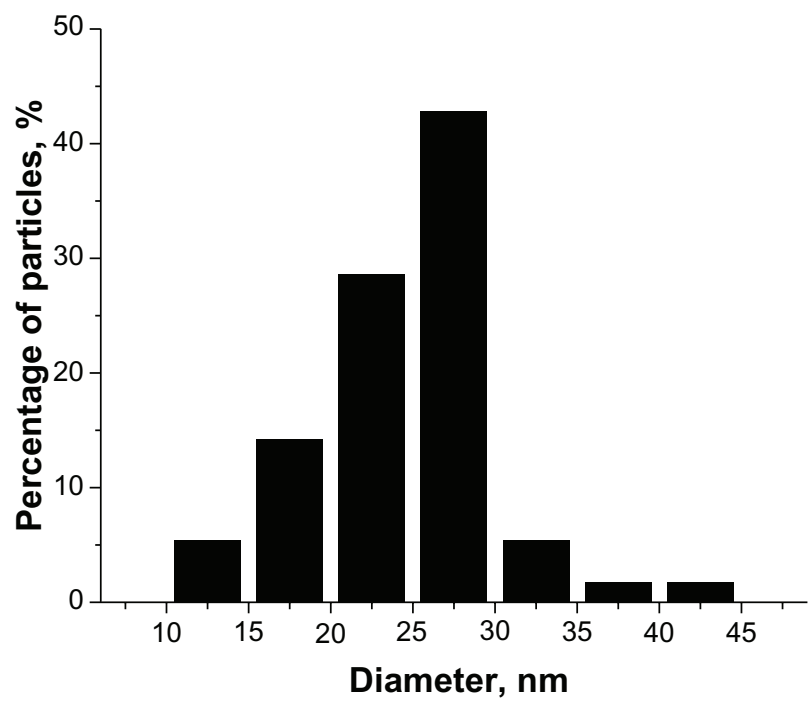

Figure 3 Histogram of size distribution for silver nanoparticles. 
A

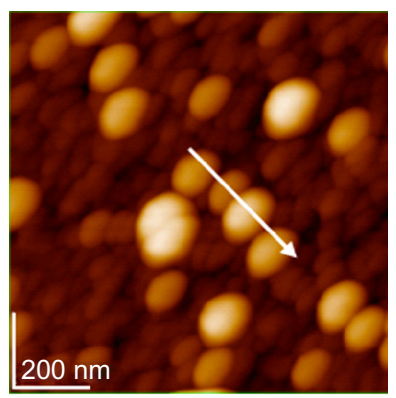

B

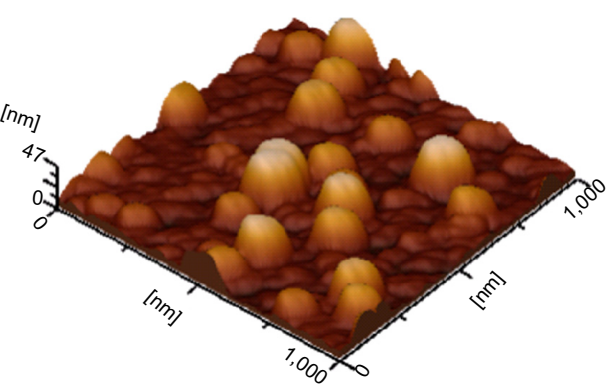

C

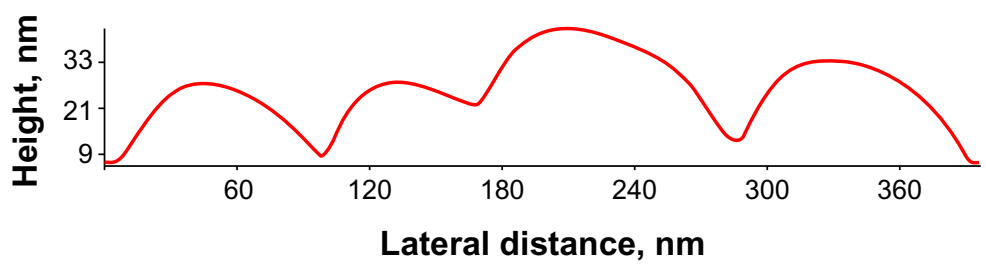

Figure 4 Atomic force microscopy images silver nanoparticles on glass; scanned area I $\mu \mathrm{m} \times \mathrm{I} \mu \mathrm{m}$ : (A) 2-D topography; (B) 3-D topography; (C) profile of the cross-section along the arrow in panel $\mathbf{A}$.

tendency to form small aggregates of particles is manifest, and is presumably due to asparagine, which could favor the self-assembly of NPs, as many amino acids do. ${ }^{36,38}$ The sizes of a great number (hundreds) of particles were measured on the TEM images, and a histogram providing the size distribution of AgNPs is given in Figure 3. The average size (diameter) of the particles was $24.5 \pm 5.3 \mathrm{~nm}$. This finding indicates a fairly narrow distribution, as compared with biogenic methods, which mostly yield a broad range of particle' sizes. ${ }^{16,24}$ This is comparable with the distributions resulting
A

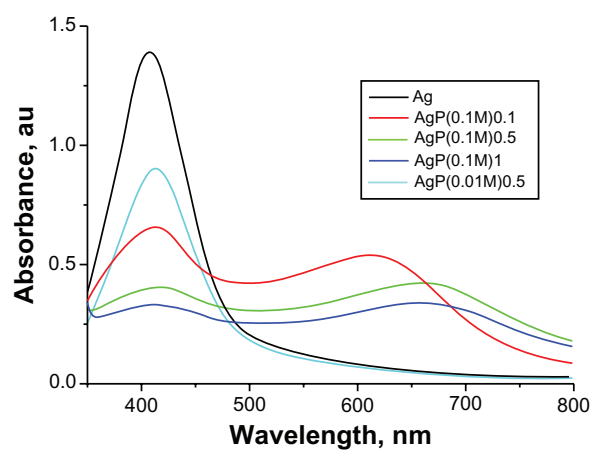

B

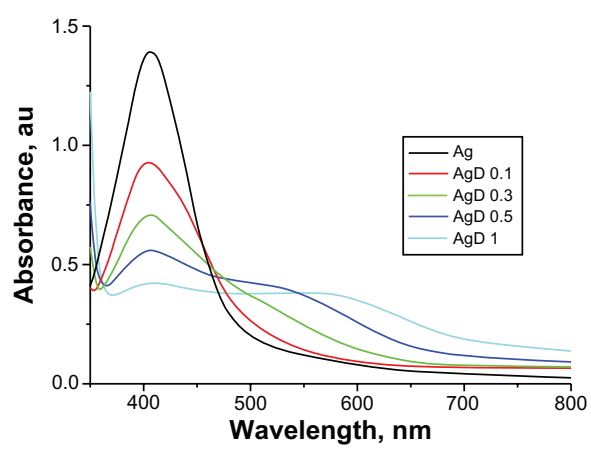

C

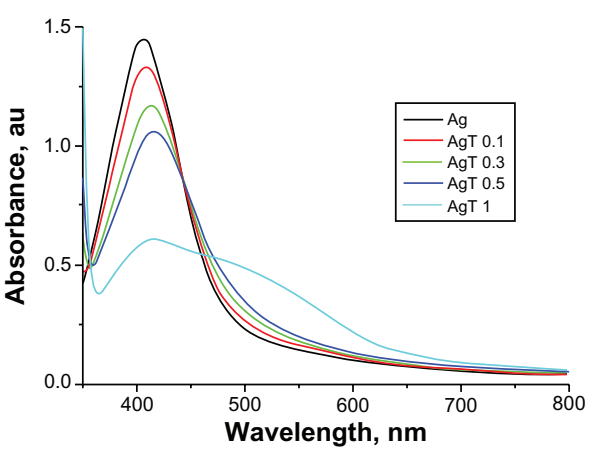

Figure 5 Optical absorption spectra of silver nanoparticles with $10^{-2} \mathrm{M}$ and $10^{-1} \mathrm{M}$ procaine, $\mathrm{P}(\mathbf{A}), 10^{-2} \mathrm{M}$ dibucaine, $\mathrm{D}(\mathbf{B})$, and $10^{-2} \mathrm{M}$ tetracaine, $\mathrm{T}(\mathbf{C})$ solutions; volumes $(\mathrm{mL})$ of anesthetic solutions added to $2 \mathrm{ml}$ silver nanoparticles solution are indicated in the inserted frame.

Abbreviations: $\mathrm{Ag}$, silver nanoparticles; $\mathrm{AgP}, \mathrm{Ag}$ with procaine; $\mathrm{AgD}, \mathrm{Ag}$ with dibucaine; $\mathrm{AgT}, \mathrm{Ag}$ with tetracaine; au, arbitrary units. 
from other methods using glucose as reducing agent, eg, $9.62 \pm 2.46 \mathrm{~nm}^{25}$ or $5.28 \pm 1.71 .^{22}$ Since our purpose was mainly to investigate the interaction of the AgNPs with the anesthetic molecules, the size distribution of the NPs was not a critical point.

As an exemplification of AFM images, we present topographical images and a plot of the film-surface contour in a cross-section through the AgNP layer in Figure 4. It should be noted that morphologies (aggregates) observed by AFM might be rather different than those actually present in solution, as a consequence of drying and surface effect. Nevertheless, AFM images give a valuable image on the structuration of adsorbed AgNPs on the glass surface. The particle sizes on these images are about $35 \mathrm{~nm}$, rather close to the value given by TEM measurements.

The obtained AgNPs were coated with silica and asparagine in order to avoid their aggregation and as a consequence increase their stability and usefulness. The coating layer was very thin, and it is not observed in the TEM images. However, the colloidal AgNPs were highly stable and did not show any aggregation signs (eg, change in color or showing deposits of NPs, shift of the surface plasmon-resonance absorption band in the optical spectrum) even after 1 year of storage at room temperature, but kept in the dark to avoid any photochemical reactions. The final dispersion of AgNPs had a pH of about 5.5.

The high stability of the AgNPs was achieved primarily by electrostatic repulsion among the negatively charged coating layers of hydrated silica adsorbed on them, as supported by the zeta-potential measurements.

\section{Interaction of anesthetics with AgNPs}

The optical absorption spectra, given in Figure 5 for the wavelength range from 350 to $800 \mathrm{~nm}$, show the effect of adding the volumes (given in the figures, in milliliters) of anesthetic solutions to $2 \mathrm{~mL}$ colloid solution of AgNPs. The $0.5 \mathrm{~mL}$ of $0.01 \mathrm{M}$ procaine solution (Figure 5A) added in small amounts produces only a slight red shift of the absorption maximum in the optical spectrum, and the solution remains stable for a longer time (up to several days). Such a shift towards longer wavelengths is usually considered to be caused by the change in the dielectric constant in the adsorption layer on the AgNPs, the increase of the average refractive index of the environment surrounding the NPs, and by the slight increase in particle size by the adsorbed layer. ${ }^{8,38}$ Thus it is observed that the organic molecules are adsorbed on the AgNPs without producing a considerable acceleration of self-assembly.

For a higher concentration of the same anesthetic $(0.1 \mathrm{M})$, the appearance of a new red shifted broad band (maximum in the 600-700 $\mathrm{nm}$ range) is observed, characteristic of NP aggregates, while the intensity of the absorption maximum for AgNPs (at about $406 \mathrm{~nm}$ ) is considerably reduced. The color of the solution progressively changed from pale yellow to brick red. The aggregation of the
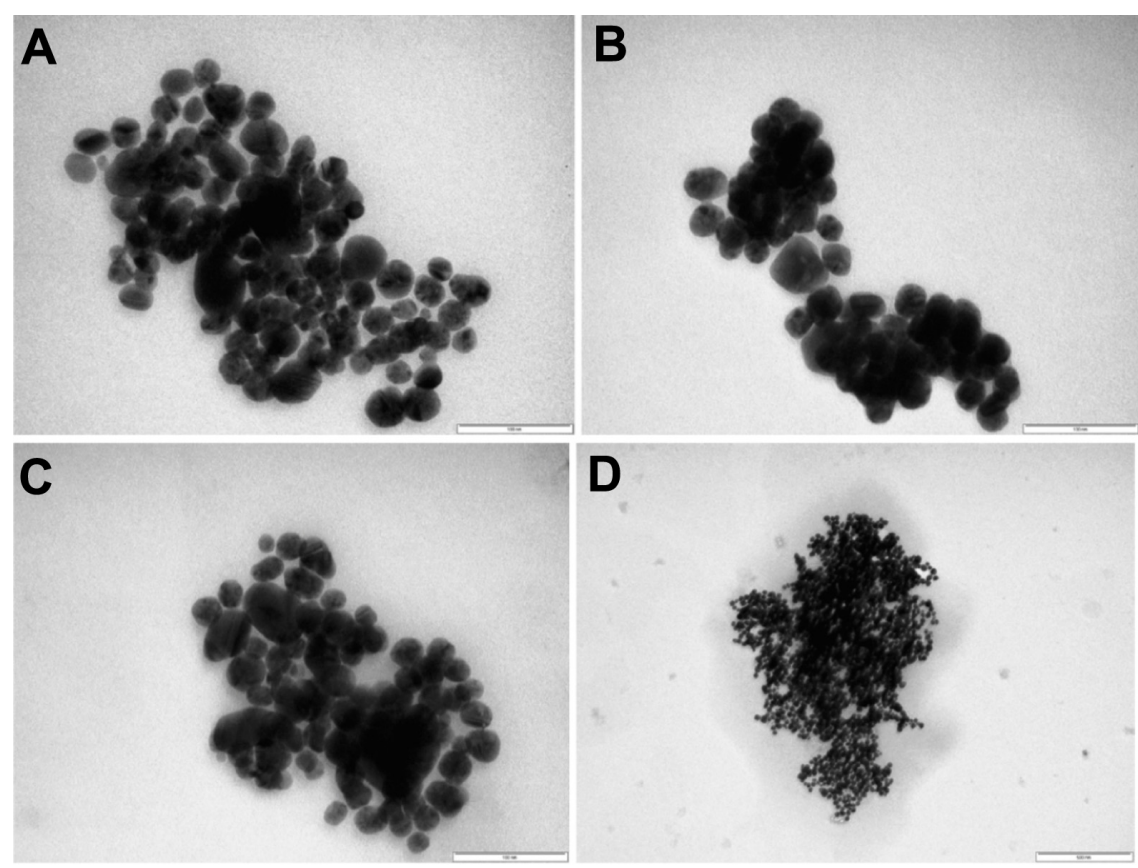

Figure 6 Transmission electron microscopy images of the silver nanoparticles with $10^{-2} \mathbf{M}$ procaine $(\mathbf{A}), 10^{-3} \mathbf{M}$ dibucaine (B), and $10^{-2} \mathbf{M}$ tetracaine $(\mathbf{C}$, $\mathbf{D})$ solutions in the I:I volume ratio, bars in the images correspond to $100 \mathrm{~nm}(\mathbf{A}-\mathbf{C})$, respectively to $200 \mathrm{~nm}$ (D). 
particles advances in time, and eventually the large silver particles sediment.

For dibucaine and tetracaine (Figure 5B and C), the effect is more pronounced than for procaine, and the aggregation of AgNPs starts at just $10^{-2} \mathrm{M}$ solution added, while the effect is the strongest for dibucaine (Figure 5B). The separation and sedimentation of large aggregates begins after just a few hours for the $0.01 \mathrm{M}$ dibucaine and tetracaine solutions added to AgNPs, while after only 2 days for procaine. Small amounts of $10^{-3} \mathrm{M}$ solutions of dibucaine and tetracaine had little effect on the AgNP solutions (not shown in Figure 5), similar to the $10^{-2} \mathrm{M}$ procaine solution.

The TEM images (Figure 6) confirm the building of AgNP assemblies mediated by the anesthetic molecules, and also the higher reactivity of dibucaine, whose $10^{-3} \mathrm{M}$ solution (Figure 6B) had an effect comparable to that of the $10^{-2} \mathrm{M}$ procaine solution (Figure $6 \mathrm{~A}$ ). The $10^{-2} \mathrm{M}$ tetracaine solution (Figure $6 \mathrm{C}$ ) also had a stronger effect than the procaine solution.

Measurements of the zeta potential of the AgNPs for the 1:1 (volumes) mixture of AgNP colloidal solution with $10^{-2}$ M procaine solution gave an average value of $\zeta=-20.3 \mathrm{mV}$ compared with the $-44.2 \mathrm{mV}$ value in the silver colloidal solution, thus indicating a diminution of the potential beyond the stability threshold of $-30 \mathrm{mV}^{37}$

AFM images evidence the advanced aggregation of AgNPs functionalized with anesthetics, which self-assembled on solid support. As an illustration, the topographical images and the plot of the film-surface contour in a cross-section through a layer of AgNPs, which were functionalized with dibucaine in $0.01 \mathrm{M}$ aqueous solution, are given in Figure 7.

As discussed elsewhere, ${ }^{35}$ the investigated anesthetic molecule tertiary amines (Figure 1) all have a tertiary nitrogen atom and another basic nitrogen atom: primary in procaine (Figure 1A), secondary in tetracaine (Figure 1C), and quinoline aromatic in dibucaine (Figure 1B). The two $\mathrm{pK}_{\mathrm{a}}$ values, for the two steps of dissociation from the dicationic form $\mathrm{BH}_{2}^{2+}$ to the monocationic $\mathrm{BH}^{+}$, respectively, from this to the neutral form (B) are between 8.8 and 9 for the tertiary nitrogen in procaine, and between 2.0 and 2.3 for its $-\mathrm{NH}_{2}$ group..$^{33,34,39}$ For the aliphatic amine group in dibucaine, $\mathrm{pK}_{\mathrm{a}}$ values between 8.5 and 10.2 were obtained, while for the quinoline, proposed $\mathrm{N}$ values were about $2^{40-42}$ or $0.44 .{ }^{34}$ Density functional theory calculations on tetracaine indicated that protonation should occur primarily at the tertiary nitrogen atom, ${ }^{43}\left(\mathrm{pK}_{\mathrm{a}}\right.$ value about $8.2-8.5,{ }^{34,44}$ ) whereas for the other $\mathrm{N}$ atom, the $\mathrm{pK}_{\mathrm{a}}$ is about 2.1-2.3. ${ }^{34,45}$

Since the working $\mathrm{pH}$ value in our experiments was about 5.5 , it is reasonable to assume the three anesthetics to be present in solution mostly as the protonated monocationic form $\mathrm{BH}^{+}{ }^{32-34}$ Thus, electrostatic attractions support their adsorption on the negatively charged AgNPs, resulting in a decrease of their zeta potential, as confirmed by our measurements. Therefore, the aggregation within the colloidal systems takes place. However, there were some differences in the effect of the three anesthetics on the AgNPs, so one should assume that specific interactions between these organic molecules and the NPs must also play a role in the self-assembly of AgNPs mediated by these molecules. As in the case of citrate-capped gold $\mathrm{NPs},{ }^{35}$ the formation of hydrogen bonds should be considered,
A

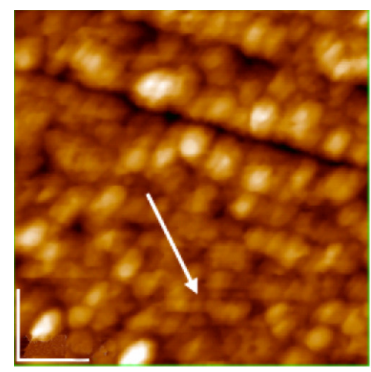

B

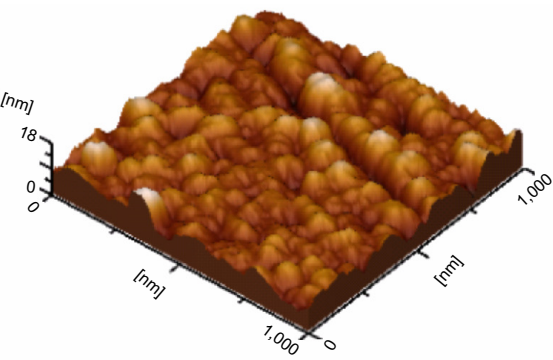

C

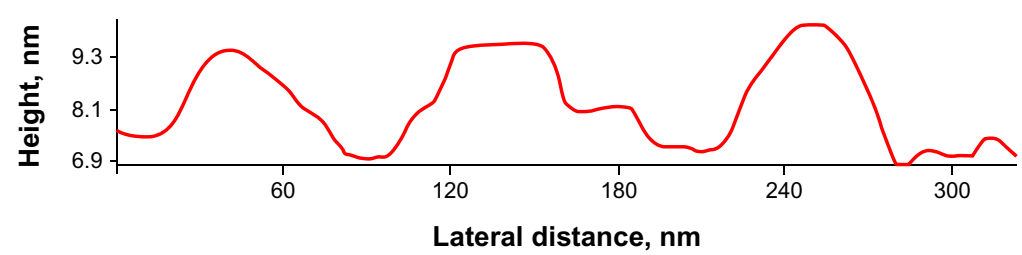

Figure 7 Atomic force microscopy images silver nanoparticles on glass in presence of $10^{-2} \mathrm{M}$ dibucaine solution; scanned area I $\mu \mathrm{m} \times \mathrm{I} \mu \mathrm{m}$ : (A) 2-D topography; (B) 3-D topography; (C) profile of the cross-section along the arrow in panel $\mathbf{A}$. 
between the anesthetic molecules and the AgNPs, by the oxygen atoms or hydroxylic $\mathrm{H}$ atoms present in their coatings. Dibucaine molecules, which appeared to be the most active in promoting the aggregation of AgNPs, in fact present the highest capacity for bridging NPs through forming hydrogen bonds: by the $\mathrm{O}$ and $\mathrm{H}$ atoms of the amide group, as well as by the $\mathrm{O}$ in the ether group, and even by the quinoline $\mathrm{N}$ atom. Also, hydrophobic interactions among anesthetic molecules cannot be ruled out. Most likely, a combination of these interactions will lead to the observed self-assemblies of AgNPs.

\section{Conclusion}

The AgNPs obtained for the first time by the method proposed in this paper proved to be quite stable over time, due to their mixed-coating layer formed by adsorbed hydrate silica and asparagine. Nevertheless, AgNPs showed high sensitivity toward the investigated anesthetic molecules. Their interactions result in modifications of the ultravioletvisible spectra and on self-assembly of the AgNPs, both in solution and on solid substrates. Therefore, they could be used in selective sensing for the detection of local anesthetics in different biological fluids. The presence of anesthetics in systems of this kind, ie, the use of AgNPs functionalized with anesthetics, would benefit the synergistic effect of the components and result in enhanced biological and medical effects of these preparations. On the other hand, colloidal systems containing AgNPs could have various medical applications, based on the well-known bactericidal properties of silver. ${ }^{12-16,46}$ Our preliminary investigations on these AgNPs adsorbed on hydroxyapatites in fact showed high antimicrobial activity. Since the reagents used are entirely nontoxic, this nanotechnology might be readily integrated for biological applications.

\section{Acknowledgments}

The authors gratefully acknowledge grants from UEFISCDI (Executive Unit for Financing of University Education, Research, Development and Innovation), Romania, PN II Program, Contract 257/2011.

\section{Disclosure}

The authors report no conflicts of interest in this work.

\section{References}

1. Rosi NL, Mirkin CA. Nanostructures in biodiagnostics. Chem Rev. 2005;105:1547-1562.

2. Zhang L, Gu FX, Chan JM, Wang AZ, Langer RS, Farokhzad OC. Nanoparticles in medicine: therapeutic applications and developments. Clin Pharmacol Ther. 2008;83:761-769.
3. El-Ansary A, Faddah LM. Nanoparticles as biochemical sensors. Nanotechnol Sci Appl. 2010;3:65-76.

4. Youns M, Hoheisel JD, Efferth T. Therapeutic and diagnostic applications of nanoparticles. Curr Drug Targets. 2011;12:357-365.

5. Bhattacharyya S, Kudgus RA, Bhattacharya R, Mukherjee P. Inorganic nanoparticles in cancer therapy. Pharmacol Res. 2011;28:237-259.

6. Kumar CSSR, editor. Biofunctionalization of Nanomaterials. Weinheim: Wiley; 2005.

7. Thanh NTK, Green LAW. Functionalisation of nanoparticles for biomedical applications. Nano Today. 2010;5:213-230.

8. Mann S, Shenton W, Li M, Connolly S, Fitzmaurice D. Biologically programmed nanoparticle assembly. Adv Mater. 2000;12:147-150.

9. Tuan VD, Wang HN, Scaffidi J. Plasmonic nanoprobes for SERS biosensing and bioimaging. J Biophotonics. 2010;3:89-102.

10. Zhang Z, Patel RC, Kothari R, Johnson CP, Friberg SE, Aikens PA. Stable silver clusters and nanoparticles prepared in polyacrylate and inverse micellar solutions. J Phys Chem B. 2000;104:1176-1182.

11. Doty RC, Yu H, Shih CK, Korgel BA. Temperature-dependent electron transport through silver nanocrystal superlattices. J Phys Chem B. 2001;105:8291-8296.

12. Panáček A, Kvítek L, Prucek R, et al. Silver colloid nanoparticles: synthesis, characterization, and their antibacterial activity. JPhys Chem B. 2006;110:16248-16253.

13. Tian J, Wong KKY, Ho CM, et al. Topical delivery of silver nanoparticles promotes wound healing. ChemMedChem. 2007;2: 129-136.

14. Geethalakshmi R, Sarada DVL. Gold and silver nanoparticles from Trianthema decandra: synthesis, characterization, and antimicrobial properties. Int J Nanomedicine. 2012;7:5375-5384.

15. He Y, Du Z, Lv H, et al. Green synthesis of silver nanoparticles by Chrysanthemum morifolium Ramat extract and their application in clinical ultrasound gel. Int J Nanomedicine. 2013;8:1809-1815.

16. Ghosh S, Patil S, Ahire M, et al. Synthesis of silver nanoparticles using Dioscorea bulbifera tuber extract and evaluation of its synergistic potential in combination with antimicrobial agents. Int J Nanomedicine. 2012;7:483-496.

17. Basu S, Jana S, Pande S, Pal T. Interaction of DNA bases with silver nanoparticles: assembly through SPRS and SERS. J Colloid Interface Sci. 2008;321:288-293.

18. Tom RT, Samal AK, Sreeprasad TS, Pradeep T. Hemoprotein bioconjugates of gold and silver nanoparticles and gold nanorods: structurefunction correlations. Langmuir. 2007;23:1320-1325.

19. Lee JS, Lytton-Jean AKR, Hurst SJ, Mirkin CA. Silver nanoparticleoligonucleotide conjugates based on DNA with triple cyclic disulfide moieties. Nano Lett. 2007;7:2112-2115.

20. Horovitz O, Tomoaia-Cotisel M, Tomoaia G, et al. Investigation on the self-assembled arrangement of silver nanoparticles in the presence of protein and aminoacids. J Optoelectron Adv Mater Symp. 2010;2: $39-43$.

21. Sadowski Z. Biosynthesis and application of silver and gold nanoparticles. In: Perez DP, editor. Silver Nanoparticles. Rijeka, Croatia: InTech; 2010:257-276.

22. Darroudi M, Ahmad MB, Abdullah AH, Ibrahim NA. Green synthesis and characterization of gelatin-based and sugar-reduced silver nanoparticles. Int J Nanomedicine. 2011;6:569-574.

23. Shameli K, Ahmad MB, Zamanian A, et al. Green biosynthesis of silver nanoparticles using Curcuma longa tuber powder. Int J Nanomedicine. 2012;7:5603-5610.

24. Loo YY, Chieng BW, Nishibuchi M, Radu S. Synthesis of silver nanoparticles by using tea leaf extract from Camellia sinensis. Int $J$ Nanomedicine. 2012;7:4263-4267.

25. Darroudi M, Ahmad MB, Zamir R, Zak AK, Abdullah SH, Ibrahim NA. Time-dependent effect in green synthesis of silver nanoparticles. Int J Nanomedicine. 2011;6:677-681.

26. Peng H, Yang A, Xiong J. Green, microwave-assisted synthesis of silver nanoparticles using bamboo hemicelluloses and glucose in an aqueous medium. Carbohydr Polym. 2013;91:348-355. 
27. Ortega-Arroyo L, Martin-Martinez ES, Aguilar-Mendez MA, Cruz-Orea A, Hernandez-Pérez I, Glorieux C. Green synthesis method of silver nanoparticles using starch as capping agent applied the methodology of surface response. Starke. 2013. Epub March 18, 2013.

28. Zsakó J, Tomoaia-Cotisel M, Chifu E, Mocanu A, Frangopol PT. Influence of stearic acid monolayers upon the procaine adsorption from underlying alkaline aqueous solutions. Biochim Biophys Acta. 1990;1024:227-232.

29. Tomoaia-Cotisel M, Cadenhead DA. Interaction of procaine with stearic acid monolayers at the air/water interface. Langmuir. 1991;7: 964-974.

30. Ashgarian B, Cadenhead DA, Tomoaia-Cotisel M. An epifluorescent microscopy study of the effects of procaine on model membrane systems. Langmuir. 1993;9:228-232.

31. Zsakó J, Tomoaia-Cotisel M, Chifu E, Mocanu A, Frangopol PT. Procaine interactions with phospholipid monolayers at the air/water interface. Gazz Chim Ital. 1994;124:5-9.

32. Zdrenghea UV, Tomoaia G, Pop-Toader DV, Mocanu A, Horovitz O, Tomoaia-Cotisel M. Procaine effect on human erythrocyte membrane explored by atomic force microscopy. Comb Chem High Throughput Screen. 2011;14:237-247.

33. Zsakó J, Tomoaia-Cotisel M, Chifu E, Albu I, Mocanu A, Frangopol PT. Protolytic equilibria in surface solutions of stearic acid, procaine and benzoic acid at the air/water interface. Rev Roum Chim. 1990;35: 867-877.

34. Zsakó J, Tomoaia-Cotisel M, Albu I, Mocanu A, Chifu E. Acid-base properties of some local anesthetics. Rev Roum Biochim. 1991;28: 33-40.

35. Mocanu A, Pasca RD, Tomoaia G, Avranas A, Horovitz O, TomoaiaCotisel M. Selective effect of procaine, tetracaine and dibucaine on gold nanoparticles. J Nanosci Nanotechnol. 2012;12:8935-8939.

36. Mocanu A, Cernica I, Tomoaia G, Bobos LD, Horovitz O, TomoaiaCotisel M. Self-assembly characteristics of gold nanoparticles in the presence of cysteine. Colloids Surf A Physicochem Eng Asp. 2009;338:93-101.
37. Hunter RJ. Zeta Potential in Colloid Science: Principles and Applications. London: Academic Press; 1981.

38. Tomoaia G, Frangopol PT, Horovitz O, Bobos LD, Mocanu A, Tomoaia-Cotisel M. The effect of arginine on gold nanoparticles in colloidal solutions and in thin films. J Nanosci Nanotechnol. 2011;11: 7762-7770.

39. Babić S, Horvat AJM, Mutavdžić-Pavlović D, Kaštelan-Macan M. Determination of $\mathrm{pKa}$ values of active pharmaceutical ingredients. Trends Anal Chem. 2007;26:1043-1061.

40. Lee AG. Effects of charged drugs on the phase transition temperatures of phospholipid bilayers. Biochim Biophys Acta. 1978;514:95-104.

41. Mayer LD, Bally MB, Hope MJ, Cullis PR. Uptake of dibucaine into large unilamellar vesicles in response to a membrane potential. J Biol Chem. 1985;260:802-806.

42. Chyan YG, Hsiao MW, Catuara CM, Lin CT. Photophysical and redox properties of dibucaine and primaquine: a comparison study. $J$ Phys Chem. 1994;98:10352-10357.

43. Bernardi RC, Gomes DEB, Pascutti PG, Ito AS, Ota AT. Theoretical studies on water-tetracaine interaction. Int J Quantum Chem. 2006;106:1277-1282.

44. Shibata A, Ikawa K, Terada H. Site of action of the local anesthetic tetracaine in a phosphatidylcholine bilayer with incorporated cardiolipin. Biophys J. 1995;69:470-477.

45. Fernández MS, Calderón E. The local anaesthetic tetracaine as a quencher of perylene fluorescence in micelles. $J$ Photochem Photobiol B. 1990;7:75-86.

46. Lara HH, Garza-Treviño EN, Ixtepan-Turrent L, Singh DK. Silver nanoparticles are broad-spectrum bactericidal and virucidal compounds. J Nanobiotechnology. 2011;9:30.
International Journal of Nanomedicine

\section{Publish your work in this journal}

The International Journal of Nanomedicine is an international, peerreviewed journal focusing on the application of nanotechnology in diagnostics, therapeutics, and drug delivery systems throughout the biomedical field. This journal is indexed on PubMed Central, MedLine, CAS, SciSearch $\AA$, Current Contents ${ }^{\circledR} /$ Clinical Medicine,

\section{Dovepress}

Journal Citation Reports/Science Edition, EMBase, Scopus and the Elsevier Bibliographic databases. The manuscript management system is completely online and includes a very quick and fair peer-review system, which is all easy to use. Visit http://www.dovepress.com/ testimonials.php to read real quotes from published authors. 